\title{
THE CIRCULATORY EFFECTS PRODUCED IN A PATIENT WITH PNEUMOPERICARDIUM BY ARTHICIALLY VARYING THE INTRAPERICARDIAL PRESSURE
}

\author{
J. D. Adcock, M.D., R. H. Lyyons, M.D., And J. B. Barnwell, M.D. \\ AnN ARbor, Mrch.
}

$\mathrm{T}$ HE present understanding of the circulatory effects of pericardial effusion is based upon the work of Cohnheim. ${ }^{1}$ He noted a rise in venous pressure and a fall in the arterial blood pressure when he increased the intrapericardial pressure by introducing oil into a dog's pericardium. This has since been confirmed by others on many different laboratory animals. In man, however, studies of the effects of increased intrapericardial pressure on the dynamies of the circulation have been limited to a few isolated observations. On two occasions, in the same patient, Stewart, Crane, and Deitrich ${ }^{2}$ made simultaneous observations of the intrapericardial pressure and the venous pressure. They also demonstrated a reduetion in the venous pressure and a proportional increase in the cardiac output following paracentesis of the pericardium. Caughey, ${ }^{3}$ and others, likewise demonstrated a reduction in the venous pressure after pericardial paracentesis in cases of pericardial effusion. Zuccola ${ }^{4}$ measured the reduction in intrapericardial pressure following pericardial paracentesis. We have had the opportunity of studying the effects of a sequenec of ehanges in the intrapericardial prcssure on the human circulation under conditions more readily controlled.

A twenty-year-old white woman was admitted to the University of Michigan Hospital in July, 1938, with tuberculous polyserositis. Therapeutic pneumopericardium and left-sided therapeutic pneumothorax were established. Following this she improved, and for three months prior to this study her condition was relatively stable. There was no dyspnea, cyanosis, or edema; the ascites, which was present on admission, disappeared after the establishment of the pneumopericardium and had not recurred. The liver, which had been ennsiderably enlarged, became smaller, but could still be felt three fingerbreadths below the eostal margin. The roentgenogram, which was taken twenty days before this study, showing the pneumopericardium and left-sided pneumothorax, is reproduced in Fig. 1. In the attempt to maintain a dry pneumopericardium, an opportunity was presented to establish the limits of pressure which would not unduly embarrass the circulation. Consequently, observations were made of the changes in pulse rate, respiratory rate, arterial pressure, venous pressure, and circulation time when the intrapericardial pressure was altered over a fairly large range by the injection of air.

\section{METHODS}

By fluoroscopic obscrvation it was found that a needle could be introduced safely into the air-containing pericardial sac through the subxiphoid route with the patient in the supine position. With the needle in place, the intrapericardial pressure

From the Tuberculosis Unit, Department of Internal Medicine, University Hospital, University of Michigan, Ann Arbor.

Received for publication July 8, 1939. 
could then be varied by the introduction or removal of air by means of a pneumothorax apparatus. A $\mathrm{Y}$ tube from the needle permitted measurements of the intrapericardial pressure on a water manometer and simultaneous tambour recording on a kymograph of the pressure changes produced by the respiratory and eardiac cycles. The Erlanger apparatus was used to make a kymographic record of the pulse in the leg. The principle employed in the Erlanger apparatus was also used to maintain a relatively constant sensitivity of the tambour connected with the intrapericardial space throughout the period of observation. To accomplish this, a small balloon in a glass chamber, which could be adjusted to atmospheric pressure, was placed in the circuit, and this permitted changes in the intrapericardial pressure without changes in the recording level of the tambour. The pulse rate was also counted by palpating the radial artery. Arterial pressure was measured with a mercury manometer by palpation of the radial pulse, since the auscultatory method was not satisfactory in this patient. The respiratory rate was counted for periods of one minute and also recorded on the kymograph. The venous pressure measurements were made by the direct method, as modified by Tyyons, Kennedy, and Burwell, 5 using the right antecubital vein. Circulation time was measured by the arm-to-tongue method, using decholin.

The intrapericardial pressure was increased in steplike fashion by the addition of air to the pericardial sac. After each change in pressure, time was allowed for apparent stabilization of the consequent circulatory changes.

It should be made clear that in this study the substance used to elevate the intrapericardial pressure was air. As air, in contradistinction to Huid, is easily compressible and has a lower viscosity, pneumopericardium and hydropericardium may well have different effects upon ventricular filling, even at the same pressure levels. The pressure relationships reported here, therefore, may not be directly transferable to pericardial effusion, but the direction of the changes will be the same.

At the time of these observations the patient suffered from some degree of impairment of cardiac function, as evidenced by the slightly elevated venous pressure, tachycardia, and hepatomegaly. The abnormally high intrapericardial pressure that was originally present had been somewhat reduced by the replacement of the effusion with air. Nevertheless, in order to maintain the pneumopericardium, the intrapericardial pressure had been kept above almospheric pressure. Some impairment in cardiac function conld therefore be expected, since Beck and Isaac ${ }^{6}$ have demonstrated that merely exposing the heart to atmospheric pressure produces a diminution in cardiac output in dogs.

\section{RESULTS AND DISCUSSION}

The variations of venous pressure, pulse rate, arterial pressure, and circulation time with changes in the intrapericardial pressure are illustrated in Graph I. There were no significant changes in the rate or character of respiration throughout the entire period of observation, hence it is not included in the graph.

Intrapericardial Pressure.- On entering the pericardium, the pressure was found to fluctuate between $+50 \mathrm{~mm}$. of water during inspiration and $+100 \mathrm{~mm}$. during expiration. This was in accord with many previous observations on this patient. Table I shows the steplike changes in intrapericardial pressure, the amount of air added or removed to produce each change, and the inspiratory, expiratory, and mean intrapericardial pressure at each level. For convenience in diseussing the 


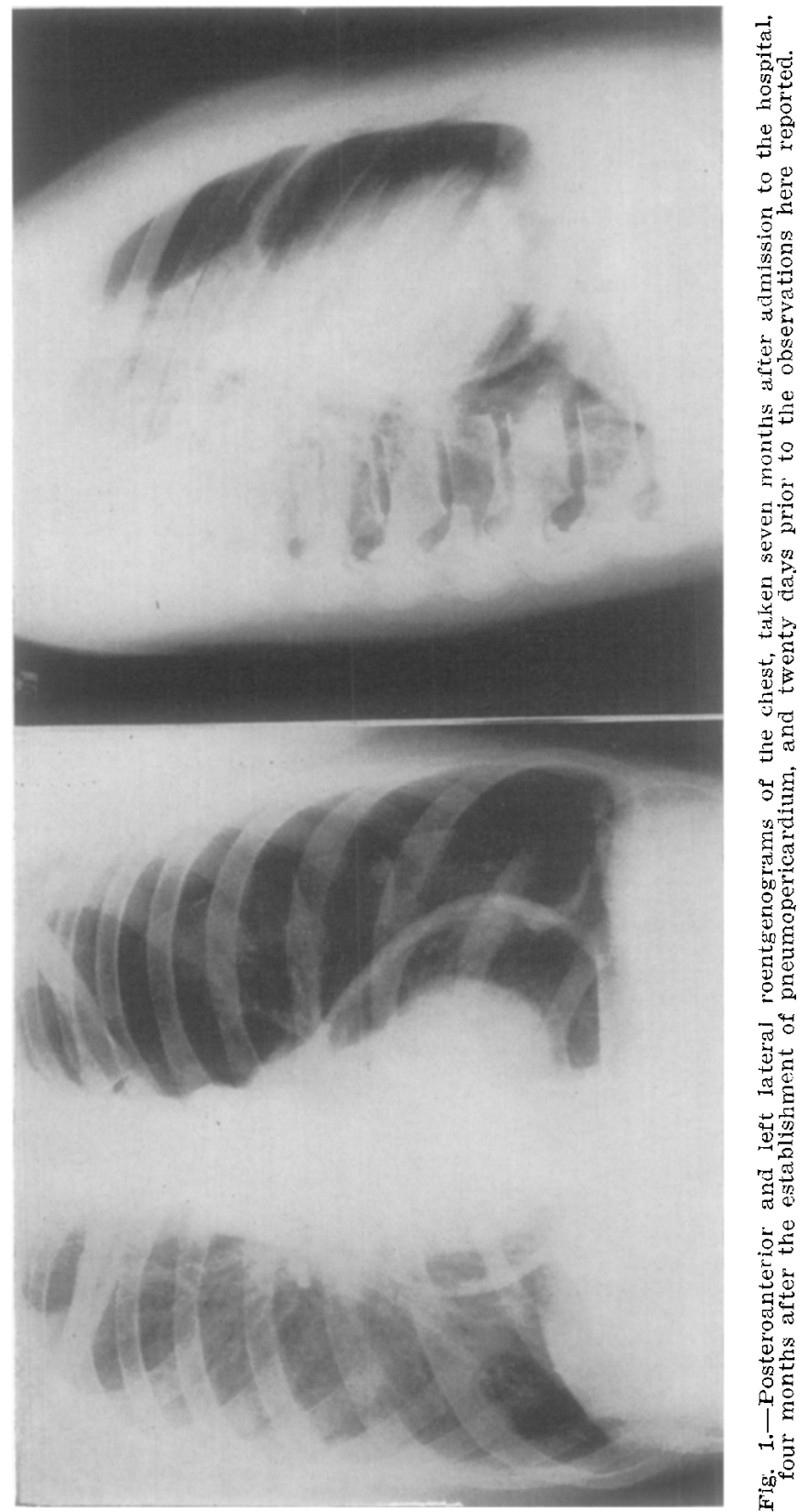


various pressure levels hereafter, the mean intrapericardial pressure will be used.

Once a pressure level in the pericardium was established, it remained constant until altered by further addition or removal of air. There was no evidence of a change in pressure as a result of pericardial stretch, although this has been noted in experimental animals. The fluctuations in intrapericardial pressure caused by the heartbeat were too rapid to be measured on a water manometer, but they were well recorded on the kymograph (Fig. 2). The respiratory fluctuations in intrapericardial pressure, since they were slower, could be measured on a water manometer as well as recorded on the kymograph. Thus, a comparison of the recorded fluctuations caused by the heartbeat with those caused by respiration gave a rough index of the pressure changes within the pericardium produced by systole and diastole. As the intrapericardial pressure was increased, the changes in pressure caused by the heartbeat were less marked, suggesting that there was a decrease in diastolic filling.

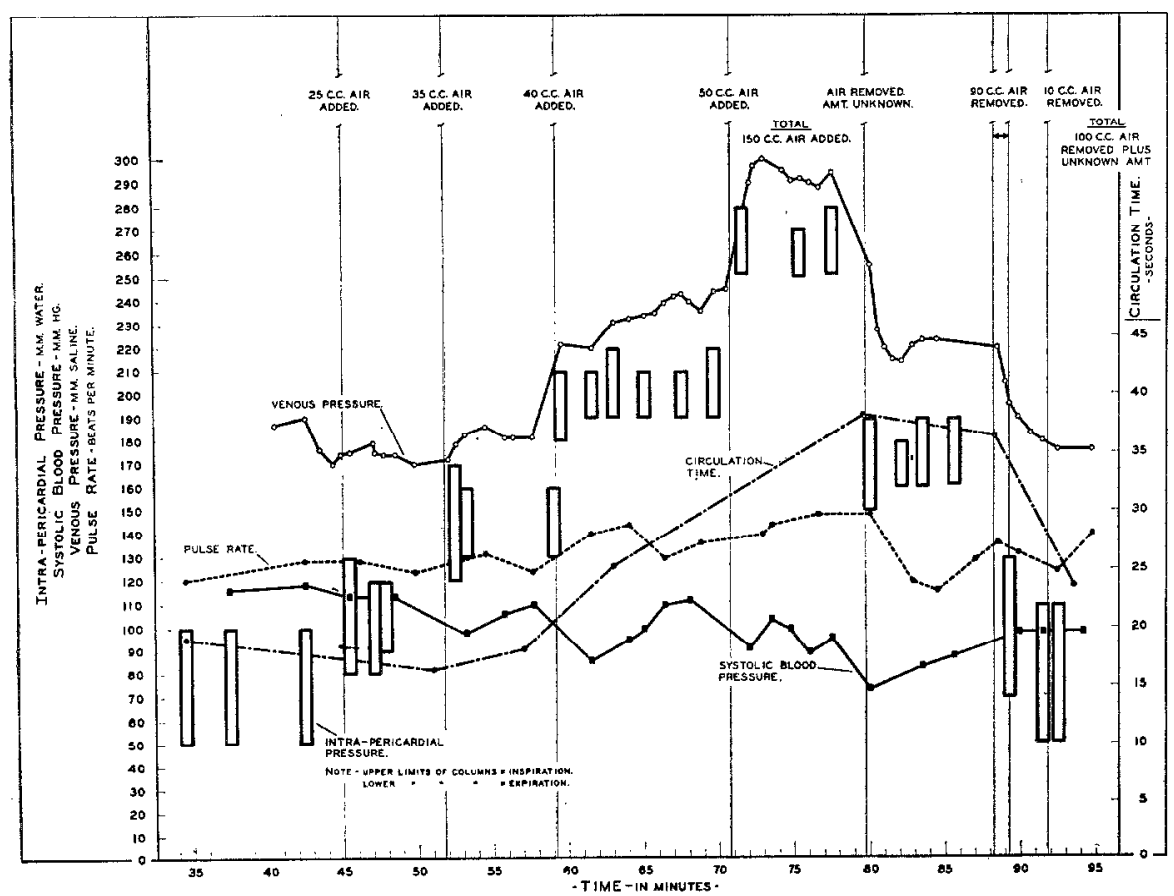

Graph I.-Each measurement of intrapericardial pressure is represented by a rectangle which lliustrates the range of pressure chinge caused by respiration. For the purpose of simplicity, the pulse rate and arterial pressure are placed on the same scale as intrapericardial pressure. This has the result of minimizing the graphic representation of the changes. The time, in minutes, is from the beginning of the observations.

As the intrapericardial pressure was increased, the fluctuations caused by respiration were decreased. Thus, with a mean intrapericardial pressure of $75 \mathrm{~mm}$. of water the respiratory fluctuations were in the region of $50 \mathrm{~mm}$., but at higher pressures these fluctuations were reduced to $25 \mathrm{~mm}$. It seems possible in this case that the decrease of intra- 
pericardial pressure accompanying inspiration facilitated diastolic filling of the heart. Thus, a reduction in the respiratory fluctuation of intrapericardial pressure may be a factor in determining the level of intrapericardial pressure at which severe tamponade will occur.

Venous Pressure.-It can be seen in Graph II that, at the beginning of the observations, the venous pressure was approximately $95 \mathrm{~mm}$. of water above the mean intrapericardial pressure. Increasing intrapericardial pressure to $145 \mathrm{~mm}$. did not affect the venous pressure appreciably. At this point, however, the difference between venous pressure and intrapericardial pressure was about 35 to $40 \mathrm{~mm}$. of

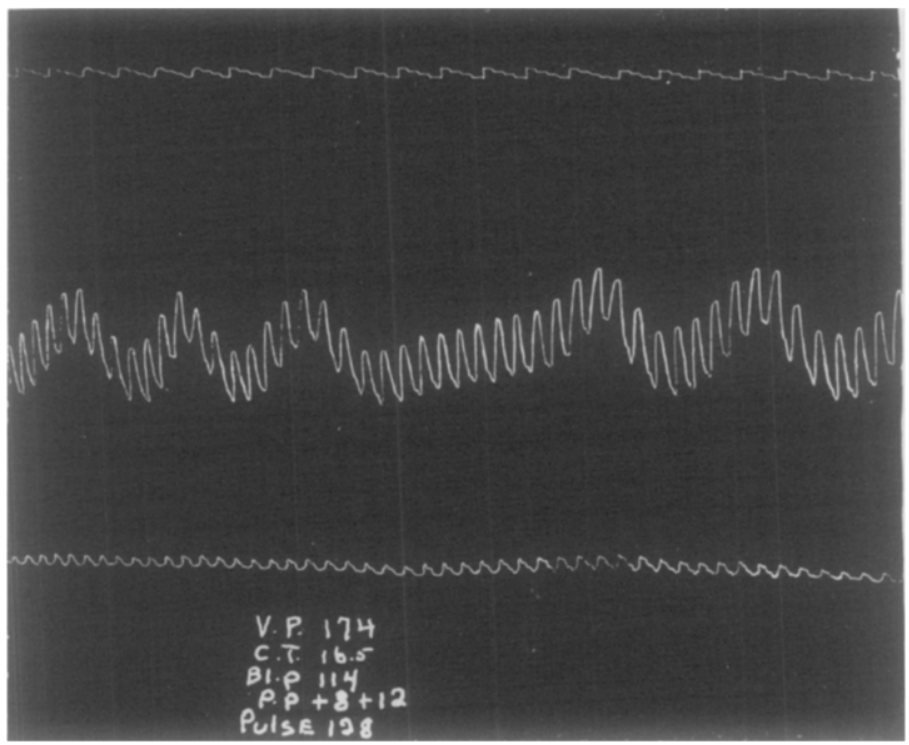

Fig. 2.-This section of tracing was taken between forty-five and forty-seven minutes after the beginning of the study. The center tracing shows the fluctuations in intrapericardial pressure with the respiratory and cardiac cycles. The lower tracing is of the arterial pulse, taken by means of the Erlanger apparatus. The upper tracing is time in secunds.

V.P. $=$ venous pressure in mm. of saline.

$C . T .=$ circulation time in seconds.

Bl.P. = systolic blood pressure in mm. of mercury.

F.P. - intrapericardial pressure in crr. of waler.

Pulse $=$ pulse rate in beats per minute.

water. A subsequent increase in intrapericardial pressure produced a proportionate increase in the venous pressure. With the final elevation of the intrapericardial pressure to $265 \mathrm{~mm}$., the increase in venous pressure was not proportionate, and the difference between them fell to $25 \mathrm{~mm}$. After about six minutes under these conditions, unequivocal signs of severe tamponade became evident. The patient appeared rather pale, there was cyanosis of the mucous membranes, and she became quite faint. The pulse became rapid and thready, and the arterial pressure fell. It appears plausible that in this case a venous pressure of 35 to $40 \mathrm{~mm}$. above the pressure in the pericardium was necessary for the maintenance of an adequate circulation. 
When the pericardial pressure was reduced by the rapid removal of air, the venous pressure fell, but remained 40 to $50 \mathrm{~mm}$. above the intrapericardial pressure, and the symptoms of severc tamponade were quickly relieved. Further reduction in the intrapericardial pressure, to approximately its original level, was accompanied by a fall in venous pressure, also to its original level.

Circulation Time.-As is shown in Graph III, the circulation time increased from nineteen seconds to a maximum of thirty-eight seconds. As was noted with venous pressure measurements, no significant changes were manifest until the intrapericardial pressure was elevated above 145 $\mathrm{mm}$. of water. This is better illustrated in Graph IV, in which the venous pressure and circulation time are plotted against the mean intrapericardial pressure.

Pulse Rate.-With each increase in the intrapericardial pressure there was an increase in the pulse rate, but the rate tended to return toward its original level after a few moments (Graph V). Like the venous pressure and circulation time, the pulse rate was not markedly affected until a mean intrapericardial pressure of $145 \mathrm{~mm}$. of water was attained. With further increases in pressure there was a decided increase in pulse rate, reaching a maximum of 148 . With the sudden release of pressure in the pericardium, just after the onset of severe tamponade, there was

TABLE I

\begin{tabular}{|c|c|c|c|c|}
\hline \multirow{2}{*}{$\begin{array}{l}\text { VOLUME AIR ADDED } \\
\text { OR REMOVED } \\
\text { (C.C.) }\end{array}$} & \multirow{2}{*}{$\begin{array}{l}\text { TOTAL AIR ADDED OR } \\
\text { REMOVED } \\
\text { (C.C.) }\end{array}$} & \multicolumn{3}{|c|}{$\begin{array}{l}\text { INTRAPERICARDIAI PRESSURE } \\
\text { MM. WA'lEH }\end{array}$} \\
\hline & & EXPIRATORY & INSPIRATORY & MEAN \\
\hline 0 & +0 & $\begin{array}{l}+100 \\
+100 \\
+100\end{array}$ & $\begin{array}{l}+50 \\
+50 \\
+50\end{array}$ & +75 \\
\hline+25 & +25 & $\begin{array}{l}+130 \\
+120 \\
+120\end{array}$ & $\begin{array}{l}+80 \\
+80 \\
+90\end{array}$ & +105 \\
\hline+35 & +60 & $\begin{array}{l}+170 \\
+160 \\
+160\end{array}$ & $\begin{array}{l}+120 \\
+180 \\
+180\end{array}$ & +145 \\
\hline+40 & +100 & $\begin{array}{l}+210 \\
+210 \\
+220 \\
+210 \\
+210 \\
1220\end{array}$ & $\begin{array}{r}+180 \\
+190 \\
+190 \\
+190 \\
+190 \\
+190\end{array}$ & +200 \\
\hline+50 & +150 & $\begin{array}{l}+280 \\
+275 \\
+280\end{array}$ & $\begin{array}{l}+255 \\
+250 \\
+255\end{array}$ & +266 \\
\hline $\begin{array}{l}\text { *Air removed. } \\
\text { Amount unknown }\end{array}$ & $?$ & $\begin{array}{l}+190 \\
+185 \\
+190 \\
+190\end{array}$ & $\begin{array}{l}+155 \\
+160 \\
+160 \\
+165\end{array}$ & +174 \\
\hline-90 & $\begin{array}{l}-90, \text { plus amount } \\
\text { unknown }\end{array}$ & +130 & +70 & +100 \\
\hline-10 & $\begin{array}{l}-100, \text { plus amount } \\
\text { unknown }\end{array}$ & $\begin{array}{l}+110 \\
+110\end{array}$ & $\begin{array}{l}+50 \\
+50\end{array}$ & +80 \\
\hline
\end{tabular}

*Air released through stopcock-not measured. 
RELATIONSHIP OF MEAN INTRA-PERICARDIAL PRESSURE TO VENOUS PRESSURE.

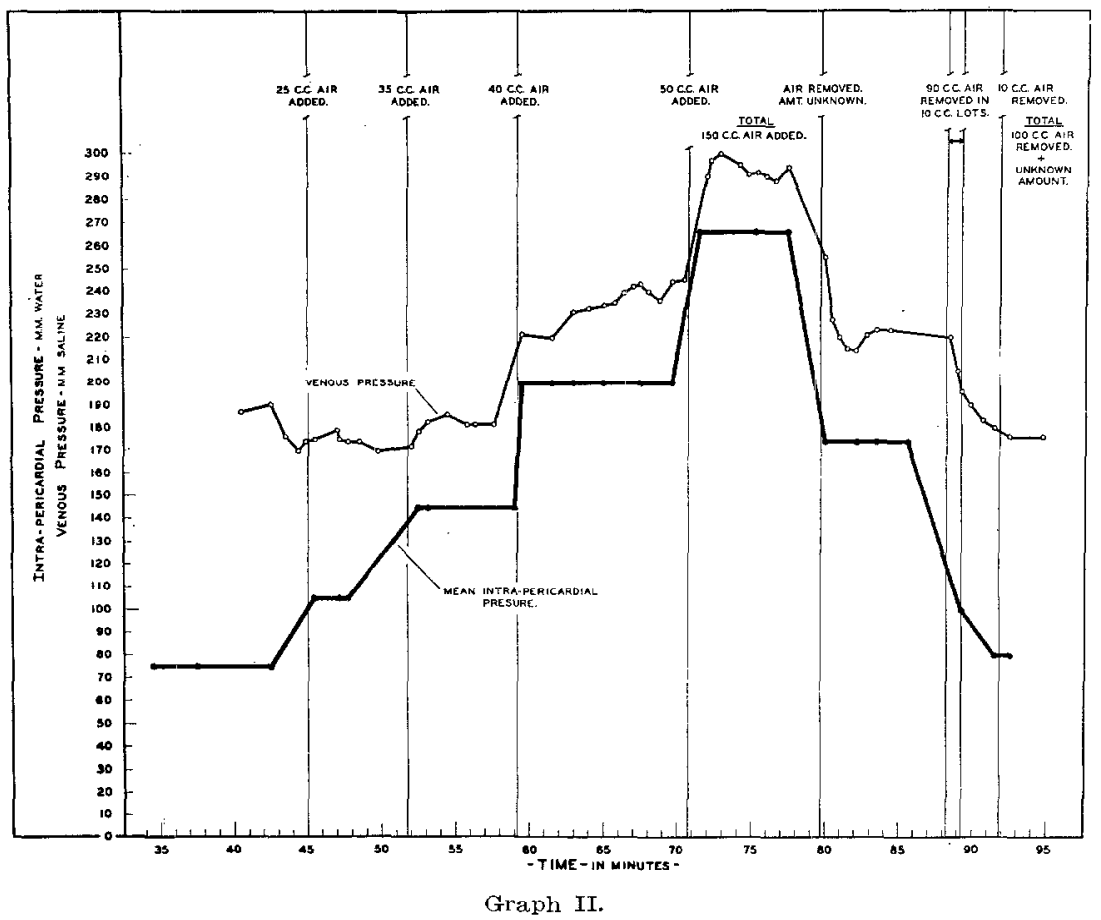

RELATIONSHIP OF MEAN INTRA-PERICARDIAL PRESSURE TO CIRCULATION TIME.

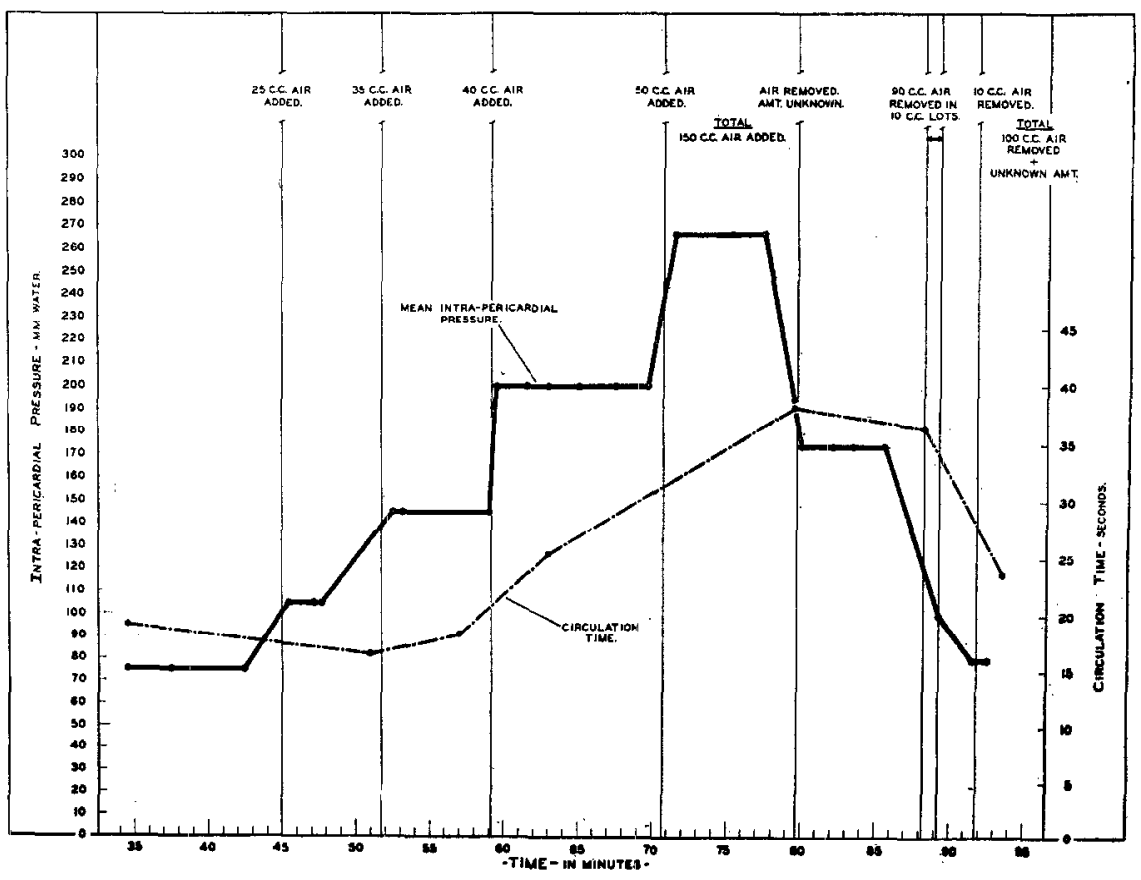

Graph III. 


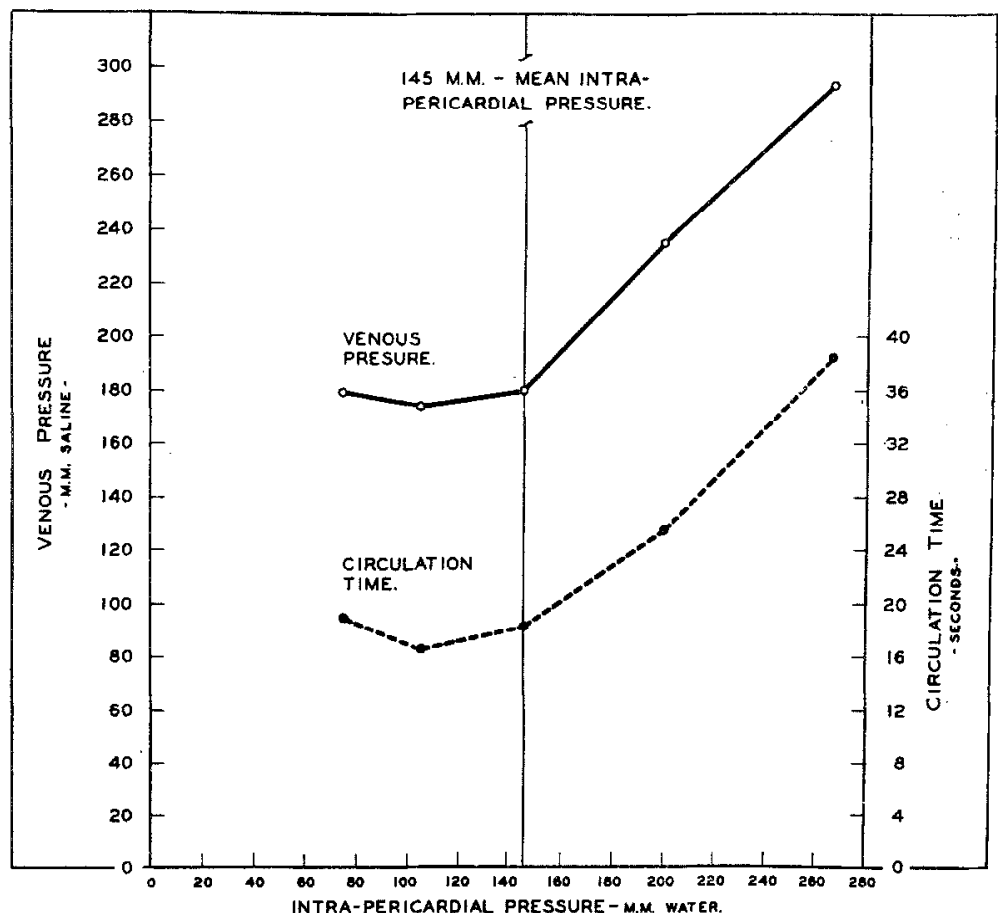

Graph IV.-The venous pressure in $\mathrm{mm}$. of saline and the circulation time in seconds (ordinate) are plotted against the mean intrapericardial pressure in $\mathrm{mm}$. of water (abscissa). It an be seen that no sionifieant changes occur in either venous pressure or circulation time until the mean intrapericardial pressure is elevated above $145 \mathrm{~mm}$. of water.

RELATIONSHIP OF MEAN INTRA-PERICARDIAL PRESSURE. TO SYSTOLIC BLOOD. PRESSURE AND PULSE RATE.

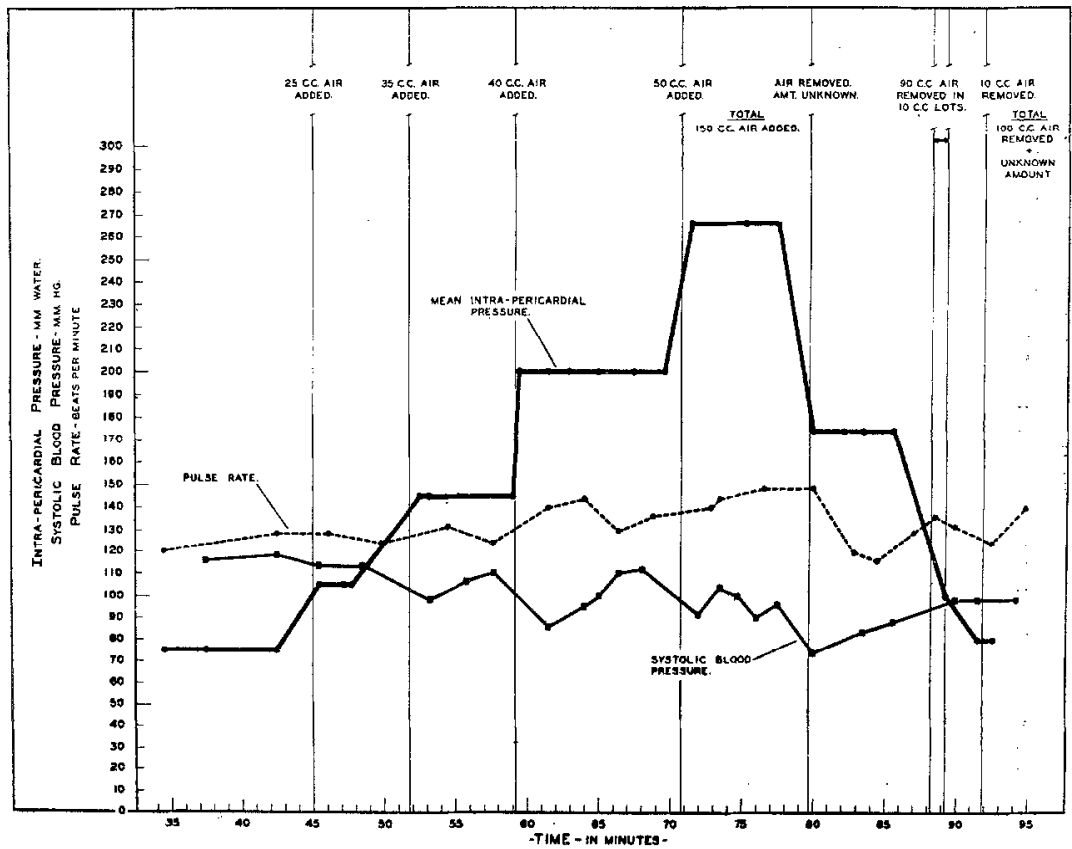

Graph V.-See legend to Graph I. 
a striking but momentary fall in the pulse rate from 148 to 116 , which was slightly below the original rate. This accompanied a rather prompt fall in the venous pressure and a diminution in the visible and palpable distention of the neck veins. This temporary fall in the pulse rate must, therefore, have coincided with a marked increase in the diastolic filling of the heart.

Arterial Pressure.-The arterial pressure tended to fall with each increase in intrapericardial pressure, and to return to its previous level in the next few moments. When the mean pressure in the pericardium was $266 \mathrm{~mm}$. of water, the arterial pressure fell slowly throughout the six minutes of observation. The low level of $74 \mathrm{~mm}$. of mercury was recorded coincident with the release of air from the pcricardium.

\section{SUMMARY}

1. Observations on changes in pulse rate, respiratory rate, arterial pressure, venous pressure, and circulation time were made with artificially produced changes in intrapericardial pressure in a patient with pneumopericardium. These relationships have been illustrated graphically.

2. The intrapericardial pressure fluctuated with respiration, and, as higher pressures were reached, these fluctuations decreased.

3. The intrapericardial pressure fluctuated with systole and diastole. Kymographie tracings were made of the fluctuations in intrapericardial pressure caused by respiration and the heartbeat. With the higher intrapericardial pressures, the changes in pressure produced by systole and diastole were less marked.

4. Significant changes in pulse rate, arterial pressure, venous pressure, and circulation time did not occur until the intrapericardial pressure was elevated to, or above, $145 \mathrm{~mm}$. of water.

5. In order to maintain the circulation, it was necessary that venous pressure exceed intrapericardial pressure by at least 35 to $40 \mathrm{~mm}$. of water.

\section{REFERENCES}

1. Cohnheim, Julius: Lectures on General Pathology, A Handbook for Practitioners and Students, Trans. from the 2 German Ed. by Alexander B. McKee, with Memoir' by Translator, Section I, The Pathology of the Circulation, London, New Sydenham Soc., 1889.

2. Stewart, II. J., Crane, N. F., and Deitrich, J. F.: Studies of the Cireulation in Pericardial Effusion, AM. HEART J. 16: 189, 1938.

3. Canghey, J. L., Jr.: A Case of Pericarditis With Effusion; Studies of Venous Pressure Changes, Bull. New York Acad. Med. 13: 1, 1937.

4. Zuceola, P. F.: Cura Della Pericardite Essudativa Col Pneumopericardio, Riforma med. 41: 607, 1925.

5. Lyons, R. H., Kennedy, J. A., and Burwell, C. S.: The Measurement of Venous Pressure by the Direct Method, AM. HEART J. 16: 675, 1938.

6. Beck, C. S., and Isaac, L.: Pneumocardiac Tamponade: Study of Effects of Atmospheric Pressure Upon Heart, J. Thoracic Surg. 1: 124, 1931. 